\title{
Effect of student transrectal palpation on early pregnancy loss in dairy cattle
}

\author{
Randall L. Bond, Lowell T. Midla, ${ }^{*}$ Eric D. Gordon, F. H. Bimbo Welker, Martey A. Masterson, \\ Dimitria A. Mathys, and Dixie F. Mollenkopf† \\ Department of Veterinary Preventive Medicine, College of Veterinary Medicine, The Ohio State University, Columbus 43210
}

\begin{abstract}
Transrectal palpation of the reproductive tract is the most common method for pregnancy determination in cattle and is considered a veterinary skill that new veterinary medicine (DVM) graduates should perform proficiently. However, using privately owned cattle to train students can be difficult because producers may believe that transrectal palpation by inexperienced students increases the risk of pregnancy wastage compared with examination by an experienced clinician. We used a randomized field trial of 1,216 healthy Holstein and Jersey cattle in 2 commercial dairy herds to estimate the effect of veterinary student transrectal palpation on early pregnancy loss. All cattle were determined to be pregnant using transrectal ultrasonography at approximately $37 \mathrm{~d}$ after artificial insemination. Cattle were then allocated into 2 groups based upon their ear tag number ( study group $=598$; control group $=618$ ) Cattle in the study group were immediately palpated after ultrasonography by a fourth-year veterinary student, whereas control cattle were not subject to any additional pregnancy assessment. For analysis, the student palpators were divided into 2 groups: students who had previously had formal palpation training via an elective bovine palpation class $(\mathrm{n}=30)$ and students who had not had palpation training $(\mathrm{n}=134)$. All cattle were reevaluated using transrectal ultrasonography approximately $70 \mathrm{~d}$ after artificial insemination. A total of $53(4.36 \%)$ animals lost their pregnancy between the first and second pregnancy assessments. Of the animals that lost their pregnancy, 26 (4.35\%) were study group cows and $27(4.37 \%)$ were control cows. Of the 26 cows documented to have had pregnancy loss within the study group, 20 out of 378 (5.3\%) had been palpated by students who had not taken the palpation elective and 6 out of $220(2.7 \%)$ had been palpated by students who had completed the elective. We found no
\end{abstract}

Received February 20, 2019.

Accepted June 7, 2019.

*Current affiliation: Merck Animal Health, Kenilworth, NJ 07033.

†Corresponding author: mollenkopf.12@osu.edu difference in pregnancy loss between student-palpated and clinician-ultrasounded cattle, supporting the safety of using privately owned animals for student bovine palpation and pregnancy diagnosis training without affecting early pregnancy loss.

Key words: veterinary training, rectal palpation, student, pregnancy loss

\section{INTRODUCTION}

Transrectal palpation of the reproductive tract is the most common method for pregnancy determination in cattle (Wisnicky and Casida, 1948; USDA, 2009), and reproductive management is the most commonly requested service provided by bovine veterinarians (Warnick et al., 2004; USDA, 2016). Surveys of bovine practitioners rank bovine transrectal palpation as an entry-level veterinary skill that they expect new veterinary graduates to perform proficiently (Morin et al., 2002; Miller et al., 2004). Being able to accomplish this task without affecting early gestation pregnancy loss is extremely important for effective reproductive cattle management (Zemjanis, 1970). As a result, teaching this skill to future bovine veterinarians is of utmost importance in the professional veterinary medicine (DVM) curriculum. However, veterinary colleges may not have the facilities or animal resources required to effectively teach this technique, because it has been reported that the palpation of more than 200 cows is needed to reach a consistent level of expertise (Bossaert et al., 2009). Most veterinary colleges must rely on the use of privately owned animals for students to achieve the level of repetition needed to learn this skill. Using privately owned cattle to train students can be difficult because producers might believe that transrectal palpation by inexperienced students increases the risk of pregnancy wastage compared with that by an experienced clinician, potentially incurring a negative financial impact on client owners. As a result, privately owned animals may not be readily available for training veterinary students. For these reasons, teaching the technique of bovine pregnancy diagnosis by transrectal palpation to veterinary students can be a challenge in an academic setting. 
Reports of the impact of pregnancy diagnosis by transrectal palpation on bovine pregnancy loss have been equivocal (Studer, 1969; Abbitt et al., 1978; Paisley et al., 1978; Vaillancourt et al., 1979; Franco et al., 1987; White et al., 1989; Thurmond and Picanso, 1993; Thompson et al., 1994; Alexander et al., 1995). However, much of the early scientific literature attempting to address this question had important shortcomings that have been described elsewhere (Romano et al., 2007, 2011). Recent studies have established that bovine pregnancy diagnosis by palpation per rectum (Romano et al., 2007, 2011) or transrectal ultrasonography (Reece et al., 1990; Kähn, 1992; Ball and Logue, 1994; Baxter and Ward, 1997) by an experienced veterinary practitioner does not increase pregnancy loss in dairy cattle. However, the effect of transrectal palpation of the bovine reproductive tract by inexperienced individuals such as veterinary students on pregnancy wastage has not been established. Our objective, therefore, was to evaluate the difference in bovine pregnancy loss between cows that were evaluated for pregnancy status using transrectal ultrasonography by an experienced clinician and those that were first evaluated by transrectal ultrasonography by an experienced clinician and then immediately palpated by an inexperienced fourth-year veterinary student. We also investigated whether student completion of a formal bovine palpation techniques course offered at The Ohio State University College of Veterinary Medicine before palpation of privately owned animals would affect palpation-related pregnancy loss. We hypothesized that cows palpated by students who completed the training course might experience more pregnancy wastage due to a more aggressive palpation technique in spite of their inexperience.

\section{MATERIALS AND METHODS}

Study protocol was performed in compliance with institutional guidelines for research on animals. Informed owner consent was obtained.

To assess the effect of DVM student palpation on early gestation pregnancy loss in dairy cattle, we enrolled healthy Holstein and Jersey dairy cows at 2 large, privately owned, commercial dairies. The lactating dairy cows were palpated approximately $37 \mathrm{~d}$ after AI unless estrus was noted previously. Transrectal ultrasonography (Easi-Scan, BCF Technologies, Bellshill, UK) was first performed on all animals by an experienced faculty veterinarian from the Ohio State University Large Animal Services (OSULAS). Determination of pregnancy was confirmed by ultrasonographic visualization of the amniotic vesicle and embryo. Following pregnancy diagnosis by ultrasonography, the cows were allocated into 2 groups based on their ear tag number. Animals with even-numbered ear tags were assigned to the student-palpated study group, and those with odd-numbered tags were assigned to serve as controls. Immediately following the transrectal ultrasonography pregnancy diagnosis, cows in the study group were palpated by one fourth-year veterinary student. Each student was blinded to the pregnancy status of the animal as determined by ultrasonography. Students were given instruction on reproductive tract palpation technique and instructed to attempt to identify 1 of the 2 possible positive signs of pregnancy for a 30-45 d pregnancy (amniotic vesicle and fetal membrane slip) in the cattle. Only cows with single embryo pregnancies were included in the study, with all twin pregnancies excluded $(\mathrm{n}=12)$. Cattle included in the control group were not subject to any additional pregnancy diagnosis by the clinician or students other than the original transrectal ultrasonography.

Pregnancy status of all study animals that had not returned to estrus was reevaluated by use of transrectal ultrasonography approximately $70 \mathrm{~d}$ after AI by an experienced OSULAS clinician. All animals that were observed displaying estrus before reevaluation of pregnancy status at $70 \mathrm{~d}$ were considered to have pregnancy loss and were not evaluated by ultrasonography. These animals were included in further analysis as having lost their pregnancy. Study animals that either died or were sold before reevaluation were excluded.

We classified the student palpators in 2 groups: those who had previously received formal bovine palpation training via an elective, one-semester bovine palpation techniques course taught at The Ohio State University College of Veterinary Medicine (VETPREV 796.17 Bovine Palpation) and those that did not have previous formal bovine palpation training. VETPREV 796.17 is a 2.00-credit-hour elective course offered during the third year of the veterinary curriculum, just before the student's clinical year. In this class, a typical student will be given the opportunity to palpate 15 to 20 animals per week of varying stages of pregnancy, including nonpregnant animals. In addition to palpation, the students have a didactic lecture period that covers a wide range of bovine reproductive topics.

A logistic regression model compared the rates of pregnancy loss between cows palpated by veterinarian only, by students who completed the palpation class, and students without the palpation class. Additionally, rates of pregnancy loss were compared between the 2 herds and between cows whose initial transrectal ultrasonography was between 30 and $35 \mathrm{~d}$ or between 36 and $45 \mathrm{~d}$. All data analyses were completed using StataCorp software (version 13, StataCorp LP, College Station, TX). 
Table 1. Proportion of dairy cows experiencing pregnancy loss by approximately d 70 post-insemination in 2 Ohio dairy herds

\begin{tabular}{|c|c|c|}
\hline Classification & $\begin{array}{c}\text { No. of } \\
\text { animals }\end{array}$ & $\begin{array}{l}\text { No. }(\%) \text { with } \\
\text { pregnancy loss }\end{array}$ \\
\hline All study animals & 1,216 & $53(4.4)$ \\
\hline \multicolumn{3}{|l|}{ Herd } \\
\hline Herd 1 & 468 & $20(4.3)$ \\
\hline Herd 2 & 748 & $33(4.4)$ \\
\hline \multicolumn{3}{|l|}{ First pregnancy detection } \\
\hline $30-35$ d post-AI & 382 & $19(5.0)$ \\
\hline $36-45$ d post-AI & 834 & $34(4.1)$ \\
\hline \multicolumn{3}{|l|}{ Study group } \\
\hline Transrectal ultrasound (US) only (control) & 618 & $27(4.4)$ \\
\hline Transrectal US plus palpation by student without elective training course & 378 & $20(5.3)$ \\
\hline Transrectal US plus palpation by student who completed elective training course & 220 & $6(2.7)$ \\
\hline
\end{tabular}

${ }^{1}$ Pregnancy loss determined by an experienced clinician using transrectal ultrasonography at approximately d 70 post-insemination or if returned to estrus before d 70 post-insemination.

\section{RESULTS}

Over 14 mo, 2 large commercial dairies provided 1,216 healthy commercial dairy cows initially diagnosed pregnant at approximately $37 \mathrm{~d}$ post-AI (mean $36.75 \mathrm{~d}$, range 30 to $45 \mathrm{~d}$ ). The study group (i.e., cows undergoing palpation by a fourth-year Ohio State University veterinary student) included 598 even-numbered ear tag cows; 618 odd-numbered ear tag cows served as the control group.

Following reevaluation at approximately $70 \mathrm{~d}$ after AI, a total of $53(4.36 \%, 53 / 1,216)$ animals had lost their pregnancy. Among the 2 herds participating in this study, 468 cows were from herd 1 and 748 were from herd 2, with pregnancy losses of 4.3 and $4.4 \%$, respectively $(P=0.91$; Table 1$)$. Of the animals that lost their pregnancy, $26(4.35 \%, 26 / 598)$ were in the study group, with pregnancy diagnosed first by a clinician using transrectal ultrasonography and then immediately palpated by a fourth-year veterinary student $(P$ $=0.98)$, and $27(4.37 \%, 27 / 618)$ were from the control group, with pregnancy diagnosed by transrectal ultrasonography only. Of the 26 cows in the study group documented to have had pregnancy wastage, 20 (5.3\%;
20/378) had been palpated by students who had not taken the bovine palpation elective course, and $6(2.7 \%$; $6 / 220$ ) had been palpated by students who completed the bovine palpation techniques training course $(P=$ 0.26 ; Table 1).

Of the 382 early-palpation cows with initial transrectal ultrasonography performed between 30 and $35 \mathrm{~d}$ post-AI, $5 \%$ experienced pregnancy loss, and $4.1 \%$ of the 834 cows palpated between 36 and $45 \mathrm{~d}$ lost pregnancies $(P=0.09$; Table 1$)$. We detected no difference in the risk of pregnancy wastage among the student groups and veterinarian-only transrectal ultrasonography (Table 2). Additionally, there was no difference $(P$ $=0.26)$ in the risk of pregnancy wastage between the 2 herds or between cows whose initial ultrasonography and palpation was between 30 and $35 \mathrm{~d}$ and those whose ultrasonography and palpation was between 36 and $45 \mathrm{~d}$ (Table 2).

\section{DISCUSSION}

In this study, palpation of the reproductive tract for pregnancy diagnosis by inexperienced students did not increase the risk of bovine pregnancy wastage com-

Table 2. Multivariable logistic regression model to estimate adjusted odds ratios (OR) for the effect of veterinary student palpation of the reproductive tract on pregnancy loss among cows in 2 Ohio dairy herds

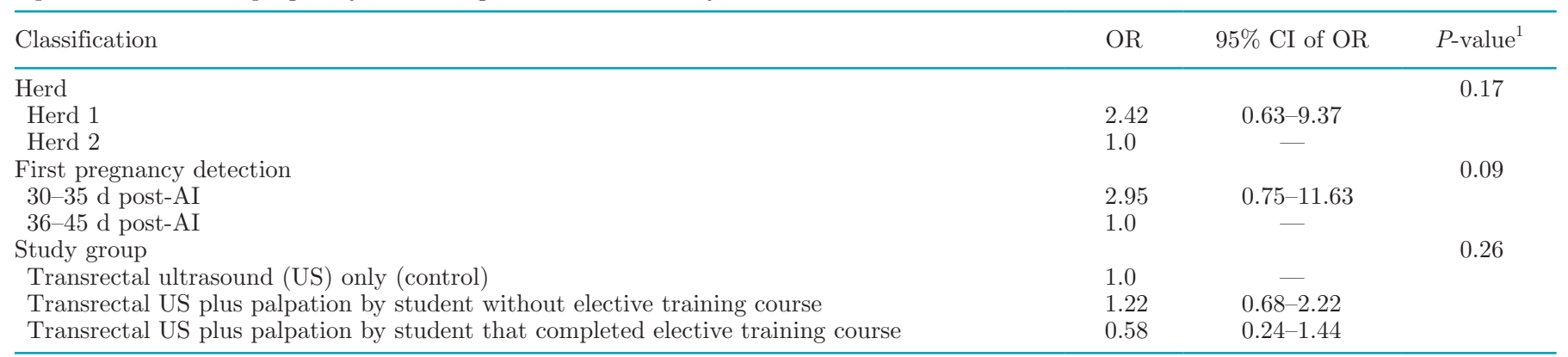

\footnotetext{
${ }^{1} P$-value determined using the likelihood ratio $\chi^{2}$ test.
} 
pared with diagnosis of pregnancy by an experienced clinician using transrectal ultrasonography. In addition, there was no difference in the risk of pregnancy loss between cows palpated by students who had participated in a formal palpation training course compared with students who had not taken the course. This result suggests that professional DVM students can be safely trained to perform bovine pregnancy diagnosis by transrectal palpation of the reproductive tract using privately owned animals without a negative financial impact on the client owners. Instructors may use this result as scientific justification for the safety of this procedure when recruiting commercial dairy producers to potentially allow veterinary students to acquire transrectal palpation training on cows in their herd. This is important because models of bovine reproductive tracts have been shown to be inadequate for student palpation training (Annandale et al., 2018).

It has been previously shown that approximately $12 \%$ of lactating dairy cow pregnancies are lost between post-AI d 28 and 60, ranging from 3.5 to $26.3 \%$ on individual farms (Wiltbank et al., 2016). Factors reported to increase early-gestation pregnancy loss in dairy cattle include infectious diseases caused by reproductive pathogens such as Leptospira borgpetersenii serovar hardjo-bovis (Grooms, 2006), bovine viral diarrhea virus (Grooms, 2006), and Neospora caninum (Pessoa et al., 2016). Noninfectious causes of early pregnancy loss can include mastitis (Fuenzalida et al., 2015), twins (Romano et al., 2007), nutritional deficiencies (Pontes et al., 2015), endocrine deficiencies (Wiltbank et al., 2014), and cow parity (Santos et al., 2009), as well as farm management practices and environmental conditions (Santos et al., 2009). We observed herd rates of pregnancy loss of 4.3 and $4.4 \%$ in the 2 study herds. This is lower than rates of pregnancy loss previously reported in other dairy cattle populations (Abbitt et al., 1978; Paisley et al., 1978; Vaillancourt et al., 1979) and could be attributed to differences in farm management or the removal of twin pregnancies in our study. In previous studies, the removal of twin pregnancies during statistical analysis reduced the percentage of embryo mortality (Romano et al., 2007). Previous studies that did not account for the increased risk in twin losses may have reported higher rates of loss.

In this study, we removed all animals that came into estrus after the first pregnancy examination and before reevaluation at $70 \mathrm{~d}$. Commercial dairies will routinely rebreed any animal showing signs of estrus during this interval; however, it should be noted that cattle can display signs of estrus without pregnancy loss (Warnick et al., 1995).

The diagnosis of bovine pregnancy by transrectal palpation of the reproductive tract requires manual detection of one or more definitive signs of pregnancy including allantochorion membrane, amniotic vesicle, placentomes, or conceptus. There is conflicting evidence of the risk of transrectal palpation of the bovine reproductive tract on iatrogenic pregnancy loss. Some data suggest that manual transrectal palpation may be an important cause of pregnancy loss (Studer, 1969; Abbitt et al., 1978; Vaillancourt et al., 1979), whereas other data provide evidence that palpation does not affect fetal loss (Romano et al., 2007). Our results offer support that the diagnosis of pregnancy by transrectal palpation has no effect on pregnancy loss in dairy cattle.

One of our hypotheses was that students who had participated in a formal bovine palpation elective training course might cause more pregnancy wastage than experienced clinicians due to overly aggressive palpation of the reproductive tract. The students included in this study completed the bovine palpation elective course 1 yr before this study. Only 30 students out of 164 in the class were able to take the course due to limitations of space and cattle numbers for teaching purposes. Students were selected to participate based on their expressed interest in pursuing a career as a food animal practitioner. This led to our hypothesis that students who took the elective course would be more highly motivated to become competent at this skill and would tend to palpate the reproductive tract more aggressively. We hypothesized that this additional aggressiveness could result in injury to the conceptus that might lead to an increase in pregnancy wastage. Our results do not support this hypothesis and indicate that student palpation of privately owned dairy cows as part of a clinical training program does not increase the risk of pregnancy loss. We found that students who completed the elective training had a lower percent pregnancy loss $(2.7 \% ; P=0.13)$ compared with students who had not taken the elective palpation training (5.3\%). This finding emphasizes the value and quality of our elective bovine palpation training course.

Our observation that there was no difference in pregnancy loss between student-palpated and control groups suggests that student palpation of the reproductive tract has no detrimental effect on bovine pregnancy, providing additional data supporting the safety of this procedure for bovine pregnancy diagnosis. Our sample size might have provided insufficient statistical power to allow us to detect biologically relevant differences between study groups. However, the small difference in rates of pregnancy loss observed in this study population is unlikely to be detected statistically, even with a much larger sample size. Access to livestock on commercial farms is critically important to a variety of animal-oriented student training programs 
at academic institutions, including professional DVM training programs. These results support the safety of using privately owned animals for student bovine palpation and pregnancy diagnosis training without affecting pregnancy loss, indicating that commercial dairy producers may allow reasonable use of their animals for teaching purposes without negative financial impact.

\section{ACKNOWLEDGMENTS}

The authors thank Thomas Wittum (The Ohio State University, Columbus) for his expertise and support of this study. No third-party funding or support was received in connection with this study or the writing or publication of the manuscript. The authors declare that there are no conflicts of interest. This research was first presented at the American Association of Bovine Practitioners (AABP) Annual Conference, New Orleans, Louisiana, in September 2015.

\section{REFERENCES}

Abbitt, B., L. Ball, G. Kitto, C. Sitzman, B. Wilgenburg, L. Raim, and G. Seidel Jr.. 1978. Effect of three methods of palpation for pregnency diagnosis per rectum on embryonic and fetal attrition in cows. J. Am. Vet. Med. Assoc. 173:973-977.

Alexander, B. M., M. Johnson, R. Guardia, W. Van de Graaf, P. Senger, and R. Sasser. 1995. Embryonic loss from 30 to 60 days post breeding and the effect of palpation per rectum on pregnancy. Theriogenology 43:551-556.

Annandale, A., C. H. Annandale, G. T. Fosgate, and D. E. Holm. 2018. Training method and other factors affecting student accuracy in bovine pregnancy diagnosis. J. Vet. Med. Educ. 45:224-231.

Ball, P. J. H., and D. D. N. Logue. 1994. Ultrasound diagnosis of pregnancy in cattle. Vet. Rec. 134:532-533.

Baxter, S. J., and W. R. Ward. 1997. Incidence of fetal loss in dairy cattle after pregnancy diagnosis using an ultrasound scanner. Vet. Rec. 140:287-288.

Bossaert, P., L. Leterme, T. Caluwaerts, S. Cools, M. Hostens, I. Kolkman, and A. de Kruif. 2009. Teaching transrectal palpation of the internal genital organs in cattle. J. Vet. Med. Educ. 36:451-460.

Franco, O. J., M. Drost, M. J. Thatcher, V. M. Shille, and W. W. Thatcher. 1987. Fetal survival in the cow after pregnancy diagnosis by palpation per rectum. Theriogenology 27:631-644.

Fuenzalida, M. J., P. M. Fricke, and P. L. Ruegg. 2015. The association between occurrence and severity of subclinical and clinical mastitis on pregnancies per artificial insemination at first service of Holstein cows. J. Dairy Sci. 98:3791-3805.

Grooms, D. L. 2006. Reproductive losses caused by bovine viral diarrhea virus and leptospirosis. Theriogenology 66:624-628.

Kähn, W. 1992. Ultrasonography as a diagnostic tool in female animal reproduction. Anim. Reprod. Sci. 28:1-10.

Miller, R. B., L. E. Hardin, R. P. Cowart, and M. R. Ellersieck. 2004 Practitioner-defined competencies required of new veterinary graduates in food animal practice. J. Vet. Med. Educ. 31:347-365.

Morin, D. E., P. D. Constable, H. F. Troutt, and A. L. Johnson. 2002 Individual animal medicine and animal production skills expected of entry-level veterinarians in bovine practice. J. Am. Vet. Med. Assoc. 221:959-968.

Paisley, L. G., W. D. Mickelsen, and O. Frost. 1978. A survey of the incidence of prenatal mortality in cattle following pregnancy diagnosis by rectal palpation. Theriogenology 9:481-491.

Pessoa, G. A., A. P. Martini, J. M. Trentin, V. C. Dalcin, C. E. P. Leonardi, F. S. F. Vogel, M. F. de Sá Filho, M. I. B. Rubin, and
C. A. M. Silva. 2016. Impact of spontaneous Neospora caninum infection on pregnancy loss and subsequent pregnancy in grazing lactating dairy cows. Theriogenology 85:519-527.

Pontes, G. C., P. L. Monteiro Jr., A. B. Prata, M. M. Guardieiro, D. A. Pinto, G. O. Fernandes, M. C. Wiltbank, J. E. Santos, and R. Sartori. 2015. Effect of injectable vitamin E on incidence of retained fetal membranes and reproductive performance of dairy cows. J. Dairy Sci. 98:2437-2449.

Reece, E. A., E. Assimakopoulos, X. Z. Zheng, Z. Hagay, and J. C. Hobbins. 1990. The safety of obstetric ultrasonography: Concern for the fetus. Obstet. Gynecol. 76:139-146.

Romano, J. E., J. A. Thompson, D. C. Kraemer, M. E. Westhusin, D. W. Forrest, and M. A. Tomaszweski. 2007. Early pregnancy diagnosis by palpation per rectum: Influence on embryo/fetal viability in dairy cattle. Theriogenology 67:486-493.

Romano, J. E., J. A. Thompson, D. C. Kraemer, M. E. Westhusin, M. A. Tomaszweski, and D. W. Forrest. 2011. Effects of early pregnancy diagnosis by palpation per rectum on pregnancy loss in dairy cattle. J. Am. Vet. Med. Assoc. 239:668-673.

Santos, J. E., H. M. Rutigliano, and M. Sá Filho. 2009. Risk factors for resumption of postpartum estrous cycles and embryonic survival in lactating dairy cows. Anim. Reprod. Sci. 110:207-221.

Studer, E. 1969. Early pregnancy diagnosis and fetal death. Vet. Med. Small Anim. Clin. 64:613-617.

Thompson, J. A., W. E. Marsh, J. A. Calvin, W. G. Etherington, H. W. Momont, and M. L. Kinsel. 1994. Pregnancy attrition associated with pregnancy testing by rectal palpation. J. Dairy Sci. $77: 3382-3387$.

Thurmond, M. C., and J. P. Picanso. 1993. Fetal loss associated with palpation per rectum to diagnose pregnancy in cows. J. Am. Vet. Med. Assoc. 203:432-435.

USDA. 2009. Pages 33-44 in Dairy 2007, part IV: Reference of dairy cattle health and management practices in the United States. N494. USDA Animal and Plant Health Inspection Service: Veterinary Services, Center for Epidemiology and Animal Health (USDA APHIS:VS, CEAH), Fort Collins, CO.

USDA. 2016. Pages 222-236 in Dairy 2014, Dairy cattle management practices in the United States, 2014. USDA Animal and Plant Health Inspection Service: Veterinary Services, Center for Epidemiology and Animal Health (USDA APHIS:VS, CEAH), Fort Collins, CO.

Vaillancourt, D., C. J. Bierschwal, D. Ogwu, R. G. Elmore, C. E. Martin, A. J. Sharp, and R. S. Youngquist. 1979. Correlation between pregnancy diagnosis by membrane slip and embryonic mortality. J. Am. Vet. Med. Assoc. 175:466-468.

Warnick, L. D., H. O. Mohammed, M. E. White, and H. N. Erb. 1995. The relationship of the interval from breeding to uterine palpation for pregnancy diagnosis with calving outcomes in Holstein cows. Theriogenology 44:811-825.

Warnick, L. D., S. Y. See, and A. Rosenbaum. 2004. Pregnancy diagnosis by rectal palpation in dairy cows: An economic comparison of four palpation schedules. Page 195 in Proc. 37th Annu. Conf. Am. Assoc. Bovine Pract. (AABP), Fort Worth, TX. AABP, Auburn, AL.

White, M. E., N. Lafaunce, and H. O. Mohammed. 1989. Calving outcomes for cows diagnosed pregnant or nonpregnant by per rectum examination at various intervals after insemination. Can. Vet. J. $30: 867-870$.

Wiltbank, M. C., A. Souza, P. Carvalho, A. Cunha, J. Giordano, P. Fricke, G. Baez, and M. Diskin. 2014. Physiological and practical effects of progesterone on reproduction in dairy cattle. Animal 8:70-81

Wiltbank, M. C., G. M. Baez, A. Garcia-Guerra, M. Z. Toledo, P. L. Monteiro, L. F. Melo, J. C. Ochoa, J. E. Santos, and R. Sartori. 2016. Pivotal periods for pregnancy loss during the first trimester of gestation in lactating dairy cows. Theriogenology 86:239-253.

Wisnicky, W., and L. Casida. 1948. A manual method for the diagnosis of pregnancy in cattle. J. Am. Vet. Med. Assoc. 113:451-452.

Zemjanis, R. 1970. Pregnancy examination. Pages 29-45 in Diagnostic and Therapeutic Techniques in Animal Reproduction. 2nd ed. The Williams \& Wilkins Co., Baltimore, MD. 